\title{
Net Ecosystem Productivity Determined by Continuous Measurement Using Automatic Sliding Canopy Chamber
}

\author{
Gun-Yeob Kim*, Seul-Bi Lee, Jong-Sik Lee, and Eun-Jung Choi
}

\author{
National Academy of Agricultural Science(NAAS), RDA, Suin-ro 150, Gwonseon-gu, Suwon-si 441-707, Korea
}

\begin{abstract}
For better understanding of carbon cycle dynamics of an agro-ecosystem, an accurate assessment of seasonal and daily $\mathrm{CO}_{2}$ flux is essential to understand the relationship between various environmental factors and crop productivity. We developed the automatic sliding canopy chamber (ASCC) system that measured continuous net ecosystem productivity (NEP) over whole growing season under the natural meteorological rhythm. The ASCC was composed of two main parts which were sliding part for measuring NEP, and automatic opening and closing chamber (AOCC) for measuring soil respiration (SR) on the soil surface. The ASCC was developed by using open flow method for measuring soil $\mathrm{CO}_{2}$ efflux. The disturbance of natural meteorological condition was minimized by opening the base frames. In the field test with barley (Hordeum vulgare L.), NEP was calculated at $140 \mathrm{mg} \mathrm{CO} \mathrm{m}^{-2} \mathrm{~h}^{-1}$ on a clear day using continuous data and eliminated the possibility of overestimate about $16 \%$ using one hour data during the day time. Unlike other small scale chamber system, installation on cropping-field made it possible to take any modifications which might be caused by natural environmental condition.
\end{abstract}

Key words: Automatic sliding canopy chamber, Automatic opening and closing chamber, Net ecosystem productivity, Carbon dioxide

\section{Introduction}

In global agro-ecosystem, soils and crops can release or store considerable quantities of carbon through soil respiration (SR) and plant growth (Raich and Schlesinger, 1992). Because agro-ecosystem is one of the greatest global carbon sources and sinks, it is an important contributor in global carbon cycling. Therefore, accurate assessment of seasonal, daily and real-time carbon fluxes in the field under natural meteorological condition is needed for successful simulation of the carbon dynamics of an agro-ecosystem.

It is also very important to understand how highly integrated process relates to crop growth and productivity such as photosynthesis, plant respiration, leaf area index, canopy architecture and other environmental factors, and how soil respiration relates to ecological factors such as plant phenology and to changes in other environmental factors such as soil temperature and water content (Katsura, 2006; Suh, 2006). Since several types

\footnotetext{
Received : 2012. 11. 2 Accepted : 2012. 11. 27

*Corresponding author : Phone: +82312900240

E-mail: gykim1024@korea.kr
}

of methods for measuring $\mathrm{CO}_{2}$ fluxes have been developed for accurate measurement, each of these systems has their own advantages and limitations, and no standardized methods are suitable for all situations. Although micrometeorological methods (Baldocchi, 1988) allow measuring carbon exchange rate (CER) under no disturbed natural environment around the plant canopy, their large spatial-scale requirement limits its applicability for typical small agronomic plot experiments (Katsura, 2006). Also, it can evaluate only net ecosystem exchange. Some canopy chamber methods are mostly used for agronomic plot experiments. These canopy chamber methods can be identified as two major systems: steady-state open system and transient-state closed chamber system (Livingstone and Hutchinson, 1995; Reicosky, 1990). Steady-state open systems are most widely used for long term measurement of field-grown plants mainly exposed to elevated $\mathrm{CO}_{2}$ or atmospheric polluting gases (e.g. Leadley and Drake, 1993). Using these chambers installed in the crop-field, it is possible to continuously monitor plant responses through the season, but possible inflow of outside air into inside the chamber limits the accuracy of CER measurement. Transient-state closed chamber systems improve the portability and allow 
enough replicates using relatively small chambers. Even these advantages, these systems require human intervention (Reicosky, 1985), and disturb natural gradient of temperature and $\mathrm{CO}_{2}$ concentration because of forced ventilation during measurement time (Held, 1990). At the same time, these systems could change the orientation pattern of leaves due to chamber installation, which is referred to as chamber effect (Reicosky, 1990), and could not reflect the plant phenology and light environmental changes due to usual cultivation in the crop field.

To minimize these problems, such as human intervention, chamber effect, and any possible environmental disturbance, the automatic sliding canopy chamber (ASCC) system has been developed based on openflow method of soil $\mathrm{CO}_{2}$ efflux measurement, to allow continuous monitoring net ecosystem productivity (NEP) from day to night time. At the same time, real time net primary productivity (NPP) can be calculated with heterotrophic respiration (HR) data from automatic opening and closing chamber (AOCC) system installed in each plot.

The objective of the study is to develop and test the ASCC system based on the open-flow method that provides high temporal resolution for continuous measurement of NEP under the natural meteorological rhythm. The study describes the design, operation, and testing of this system under natural microclimatic conditions.

\section{Materials and methods}

Chamber structure The ASCC system is composed of 4 main units: chamber, timer, valve, and pump system. The chamber system consists of two parts: one for base frame fixed at ground and the other for sliding cap (Fig. 1). The front and rear walls of the base frame and top and sidewalls of sliding cap were covered with UV-transparent polyvinyl films ( $0.15 \mathrm{~mm}$ thick, JISK6732, Mitsubishi MKV, Tokyo, Japan) that had high transmittance $(92.6 \%$ for solar radiation and $90.9 \%$ for reduction of photosynthetic photon flux density). The ends of the base frame $(1.8 \times 20 \times 1.6 \mathrm{~m}, \mathrm{~W} \times \mathrm{L} \times \mathrm{H})$ were anchored in the soil at $30 \mathrm{~cm}$ depth and divided into 5 plots. Each plot was constructed with iron pipes $(30 \times 30 \mathrm{~mm})$. Along the rail on the base frame, the sliding cap $(1.85 \times 4 \times 1.65 \mathrm{~m})$ slid one after another plot every 30 minute intervals. To minimize disturbance, nonmeasurements plots except for measuring time could be opened in order to be as close to natural environment as possible. When the plot is opened, it allows natural conditions. Five plots of base frame could be used as different experimental plot and control plot, respectively.

Timer unit, which consists of timer (H5CX-AD, Omron, Tokyo, Japan), relay (G2A-432A, Omron, Tokyo, Japan) and stepping relay (G9B-12, Omron, Tokyo, Japan), controls the measuring time of ASCC, electric power

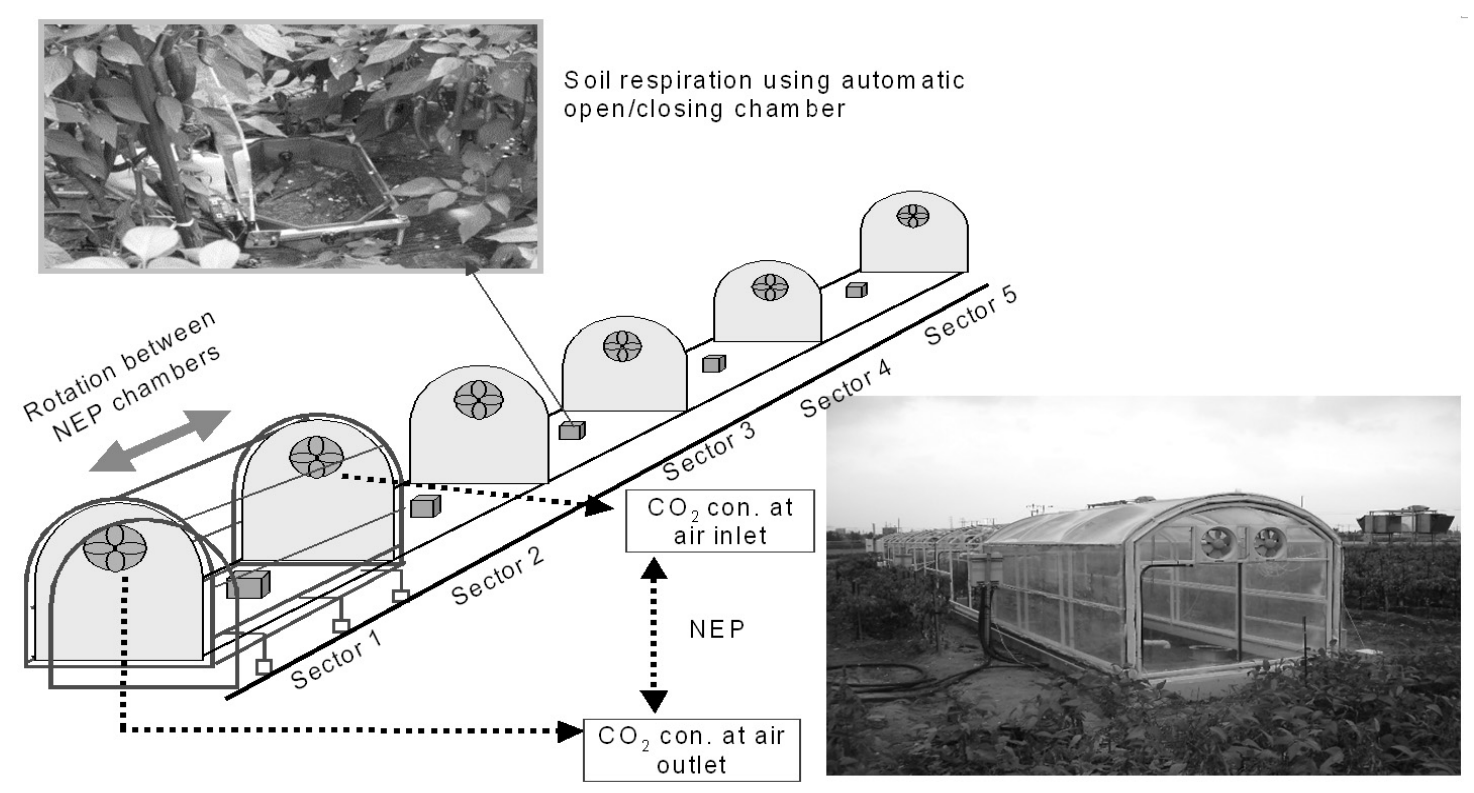

Fig. 1. Ovenview of the ASCC system: the sliding cap which has tunnel shape slide along the fixed base frame one plot to next plot. When a plot of base frame is covered with the sliding cap, ventilation fans installed in both side of the walls are operatred. Inside the ASCC, the AOCCs are installed to measure the HR. The front and rear end of the fixed frame and top and lateral side of ASCC are covered with UV-transparent polyvinyl films. 
division to solenoid valve (TV2W03, TPC Inc., Korea) and ventilation fan, limits sensor, pressure sensor of each plots, and the movement of ASCC.

Pump unit is composed of air pump (GD-6EA, Enomoto, Tokyo, Japan), flow meter (RK-1250, KoFloc, Tokyo, Japan), air filter (TPF2000, TOC Inc., Korea), water filter (Perma-pure dryer, SWG-A01-18, Asahi Glass Engineering CO., Chiba, Japan), and 3 IRGAs (LI-820, LI-Cor., Nebraska, USA: one for reference $\mathrm{CO}_{2}$ value, another for NEP and the other for HR).

Chamber operation For making open flow condition, polyurethane tubes $(6 \times 4 \mathrm{~mm} \varnothing$, Sang-a Pneumatic Co., Korea) were linked to 2 solenoid valves controlled by a DC power source, respectively. This valve unit connected to each chamber with tubes allocated the air flow sequentially to each 5 chambers in response to signals from the timer unit. When a measurement began, air pumped into silicon tube which was adhered to base frame using air compressor (UD1511, United CO., Korea), and filled up the gap between base frame and ASCC with expended silicon tube for confirming the sealing condition of ASCC. During the measurement time, the air pressure inside the silicon tube was monitored by pressure sensor (SPSA-V01, TPC, Mechatronics Corp., Korea) and kept up the internal pressure $(8.7 \mathrm{kPa})$. After measurement, the air inside the silicon tube was ventilated by vacuum pump (VF100, Today's Co., Taiwan) to smooth the movement of ASCC. The driving force of ASCC was brought by AC motor (V.S. Motor, Sung Shin Korea CO., Korea). When ASCC reached a proper position, the limit switch (BM200-DT, Autonics, Korea) that installed at the end of each plot, cut the electricity to prevent the AC motor overload, and covered the next plot.

When a plot was sealed with sliding cap, to minimize the pressure differences between inside and outside of ASCC, ventilation fans (EK(S)-250A, Hanil Electronic, Korea), which was installed at air inlet and air outlet of the each plot, generated the same amount of air inflow and out-flow. Then the pump collected $0.6 \mathrm{~L} \mathrm{~min}^{-1}$ of air from inlet and outlet of each plot, and sent to IRGAs for measuring $\mathrm{CO}_{2}$ concentration. And then the NEP was calculated from the difference of $\mathrm{CO}_{2}$ concentration between air inlet and air outlet.

Heterotrophic respiration For quantified HR, the AOCC system was installed in each plot in ASCC (see detailed in Suh, 2006). Because the AOCC installed where the root respiration (RR) could be ruled out, the measured SR implied a HR. As a result, it was possible to separate NPP from NEP and to calculate seasonal, daily and real-time NPP and NEP.

Chamber environmental condition To minimize the ASCC environment affected measurements of $\mathrm{CO}_{2}$ flux, we tested some changes in temperature and light environmental condition between inside and outside of the ASCC from 18-23 April 2005. Because of strong correlation between $\mathrm{CO}_{2}$ efflux and temperature, we monitored the changes of air and soil temperatures due to the establishments of ASCC using thermocouple $(0.32 \mathrm{~mm}$, Suzuden, Tokyo, Japan: air temperature of inside and outside chamber, above and below canopy, and soil temperature of $5 \mathrm{~cm}$ depth). In $3^{\text {rd }}$ plot, pyranometer (LI-200X, LI-Cor., Nebraska, USA) and line quantum sensor (LI-191, Li-Cor., Nebraska, USA) were installed to monitor some changes in light environment introduced by ASCC covering.

Measurement time Because of the characteristic of open flow method that with same volume air is exchanged from air inlet to outlet and the $\mathrm{CO}_{2}$ flux is calculated from the concentration differences between the air inlet and the outlet, the homogeneous condition of air inside the ASCC is very important for elimination of possible measuring errors. To examine the appropriate measuring time required, we measured the time to reach a steadystate condition inside the ASCC (Edwards and Riggs, 2003; Suh, 2006). For the measurement of NEP not only for individual crop but crop-field, the space of ASCC was larger than other canopy chambers which made it impossible to bring the chamber in the laboratory.

Instead of indoor experiment, we measured the time to reach a steady-state under non crop condition. In this condition, the whole $\mathrm{CO}_{2}$ flux from ASCC resulted from HR. As a result, $11.2 \pm 1.2$ minutes (Mean $\pm \mathrm{SD}$ ) were needed to reach a steady-state inside ASCC under $1,200 \mathrm{~L} \mathrm{~min}^{-1}$ of air flow rate. As for AOCC, the maximum measurement interval was 20 minutes, and it took 10 minutes to reach a steady-state under $1.8 \mathrm{~L} \mathrm{~min}{ }^{-1}$ of flow rate (Suh, 2006). In each case, we recorded the time until the measurement values stabilized within 5\% of a mean value. In addition, another 2 minutes were needed for the expansion of silicon tube for the sealing the gap between sliding cap and base frame. Based on 
these results for open-flow method for measuring NEP using ASCC system, we chose 30 minutes for total measurement time, and data suitable for accurately calculating NEP was obtained after 12 minutes from the starting of each measurement to 8 minutes. Then, smoke screen test was done to check any zones in which circulation stagnates inside the ASCC. In this test, smoke flowed into $\operatorname{ASCC}\left(1,200 \mathrm{~L} \mathrm{~min}^{-1}\right)$ through air inlet and was mixed by ventilation fans and vented through air outlet. The time required to be homogenous inside the ASCC with smoke was about 2 minutes and it took another 2 minutes to fully ventilate. With this test, no significant circulation stagnates was found. In an open-flow method, air was homogenously ventilated from the air inlet to outlet. As a result, any difference in airflow rates between the inlet and the outlet of the ASCC would change the air pressure so that the ASCC pressure no longer matched that of the atmosphere. To prevent the development of such pressure differences, we installed an airflow meter at the air inlet and the other at the outlet side of the pump system.

Calculation procedure With ASCC and AOCC system, NEP and HR are calculated from differences in $\mathrm{CO}_{2}$ concentration between inlet and outlet of each chamber, respectively. We calculate NEP $\left(\mathrm{mg} \mathrm{CO}_{2} \mathrm{~m}^{-2} \mathrm{~h}^{-1}\right)$ and $\mathrm{HR}\left(\mathrm{mg} \mathrm{CO} \mathrm{m}^{-2} \mathrm{~h}^{-1}\right)$ as follows:

$$
\mathrm{NEP}, \mathrm{HR}=a \cdot(c \cdot L \cdot \rho) \cdot S^{-1}
$$

where $a$ is the conversion constant; $c$ is the difference in $\mathrm{CO}_{2}$ concentrations $\left(\mu \mathrm{mol} \mathrm{mol}{ }^{-1}\right.$ ) between the air inlet and outlet of the each plot end; $L$ is the flow rate $\left(\mathrm{L} \mathrm{min}{ }^{-1}\right) ; \rho$ is the density of $\mathrm{CO}_{2}\left(\mathrm{mg} \mathrm{m}^{-3}\right) ; S$ is the ground surface area of the chamber $\left(\mathrm{m}^{2}\right)$. The constant in the equation converts the units to $\mathrm{mg} \mathrm{CO}_{2} \mathrm{~m}^{-2} \mathrm{~h}^{-1}$.

The relations among NEP, NPP and SR are as follows:

$$
\begin{aligned}
& \mathrm{NEP}=\mathrm{NPP}-\mathrm{HR} \\
& \mathrm{HR}=\mathrm{SR}-\mathrm{RR}
\end{aligned}
$$

Because we install the AOCC where RR can be ruled out from soil respiration:

$$
\mathrm{HR}=\mathrm{SR}
$$

From Eqs. (2) and (4), the NEP can be obtained as follows:

$$
\mathrm{NEP}=\mathrm{NPP}-\mathrm{HR}
$$

Then we can speculate the NPP from NEP and HR that we can not measure in real-time.

$$
\mathrm{NPP}=\mathrm{NEP}+\mathrm{HR}
$$

Each IRGA was calibrated every 2 weeks using standards zero and span gases to ensure that differences in behavior of the 2 machines would not introduce bias in results. The raw $\mathrm{CO}_{2}$ signals from the IRGAs were sampled every 10s and averaged every 2 minutes while NEP and HR were being measured, and stored in data logger (CR10X, Campbell Scientific In., Logan, UT, USA).

Field measurement The study area is in the experiment field of the National Academy of Agricultural Science $\left(37^{\circ} 15^{\prime} 22^{\prime \prime} \mathrm{N}, 126^{\circ} 59^{\prime} 24.5^{\prime \prime} \mathrm{E}\right)$, which is located in Suwon, Gyeonggi-do, Korea in the western part of the Korean peninsula. The plot size is $30 \times 10 \mathrm{~m}$, and the soil texture is clay loam soil. The experimental field was categorized into temperate climate; average annual temperature of $11.6^{\circ} \mathrm{C}$, precipitation of $1,268.1$ $\mathrm{mm}$, relative humidity of $72.7 \%$, and solar radiation of $11.78 \mathrm{MJ} \mathrm{m}^{-2}$.

The winter barley was sowed on 4 Nov. 2005 and harvested on 14 Jun 2006. The guide by National Academy of Agricultural Science was used for the fertilizer application level and culture method in barley field.

\section{Results and discussion}

Green house effect NEP is calculated by difference in $\mathrm{CO}_{2}$ concentration gradient, which could be affected by temperature. Therefore the elevated temperature caused by sealing ASCC affects the measurement error of NEP. Pickering (1993) reported that closing of canopy chamber could cause the limitation of the energy exchange with the outside temperature and induced the greenhouse effect with consequent increase in temperature regime. Less than $2^{\circ} \mathrm{C}$ of air temperature increase was reported by Garrity (1984) and Katsura (2006) with closed system, within 2-3 minutes under full sunlight 


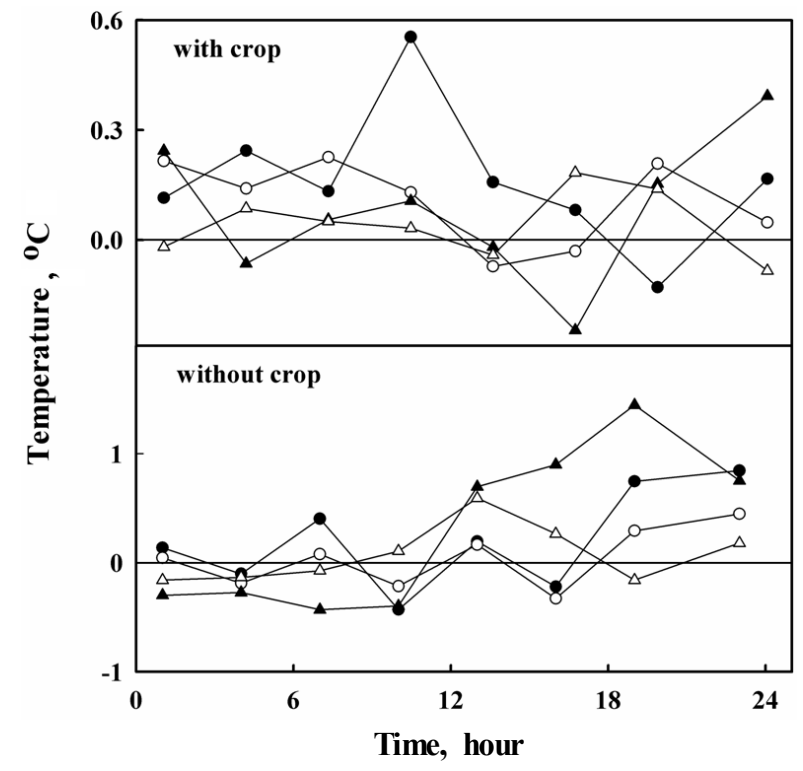

Fig. 2. The diumal variation ( $T$ inside $-T$ outside) of air temperature and soil temperature under high and low Rs condition: air temperature under high Rs (filled circle), soil temperature under high Rs (open circle), air temperature under low Rs (filled triangle), soil temperature under low Rs (open triangle).

and with $35^{\circ} \mathrm{C}$ air temperature. Instrument based on closed chamber has tendency of increasing temperature because heat resulting from solar is stored in the chamber. Wagner and Reicosky (1992) reported that both leaf and air temperature has increased by 2 to $4{ }^{\circ} \mathrm{C}$ inside the chamber within $60 \mathrm{~s}$. The results were originated that differ in naturally occurring temperature inside the chamber, pattern of wind velocity, turbulence, and heating by the fan (Steduto, 2002).

To confirm the greenhouse effect due to the sealing of ASCC, the air temperature and $5 \mathrm{~cm}$ depth underground soil temperature of inside and outside were monitored under high / low solar radiation (Rs) and with/ without crop condition, respectively (Fig. 2). Without crop conditions, it showed less than $1{ }^{\circ} \mathrm{C}$ differences in soil temperature, but almost $1^{\circ} \mathrm{C}$ difference in air temperature in both high and low Rs conditions. Even these results were in good agreement with Garrity (1984) and Katsura (2006). Also it showed less than $0.5^{\circ} \mathrm{C}$ differences in both high and low Rs conditions with crop inside the ASCC: the most of the time when we used the ASCC system is cultivation season with growing crops.

\section{Verification of light conditions by ASCC system} Because solar radiation (Rs) is one of the major environmental factor for determining the plant eco-physiological

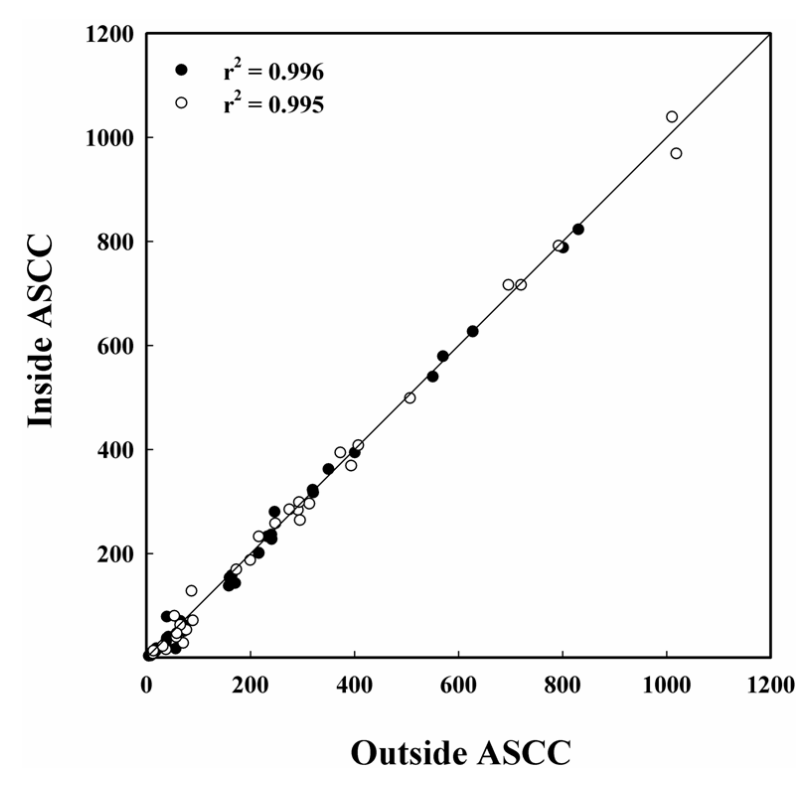

Fig. 3. Correlation between inside and outside light condition of ASCC system on typical clear days: filled circle indicate Rs inside and outside ASCC system and open circle indicate Rp inside and outside ASCC system. Inide Rs ans Rp was measured with LI-200X and LI-191B, respectively. Outside Rs and Rp was measured with portable LI-185B.

characteristic such as photosynthesis, any changers in Rs causes the measurement error. In general, the solar radiation that reaches plants inside canopy chambers tends to be reduced by the absorbance, transmittance, reflectance, and amount of frame material used in the chamber construction (Weinstock, 1982). Ten to twenty percent of incident Rs reduction was reported in the lecture (Leadley and Drake, 1993; Pickering, 1993; Reicosky, 1983; Weinstock, 1982). Also the 10-20\% reduction of photosynthetic photon flux density (PPFD: Rp) inside canopy chamber was reported (Held, 1990; Leadley and Drake, 1993; Musgrave and Moss, 1961; Pickering, 1993).

As for ASCC, we painted the frame white to avoid the any disturbance of light condition by frame material and used UV-transparent polyvinyl films. The test for evaluating the reduction effect of Rs and Rp was done every 2 hours on typical clear days (Fig. 3). At the same time, the Rs and Rp for outside the ASCC were measured by portable light meter (LI-185B, LI-Cor.). The results of light condition test of ASCC were given in Fig. 4. The average reduction of Rs due to ASCC was found to be $7.4 \%$, which was less than what found by Weinstock (1982), Leadley and Drake (1993), and Steduto (2002), i.e. 10-20\%. While it was in agreement with the result of Reicosky (1983), 8-10\%, using Plex- 


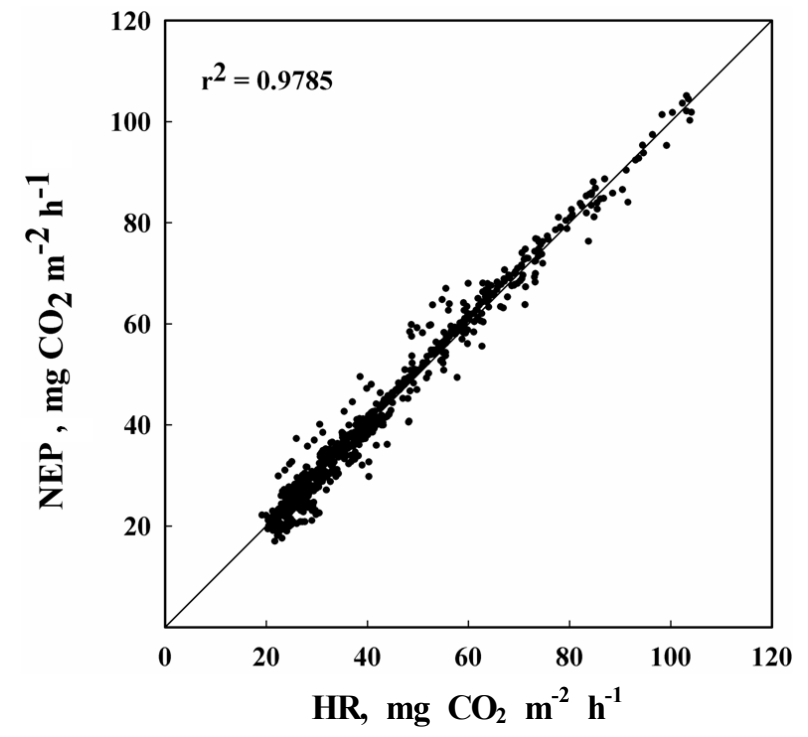

Fig. 4. Regression of NEP vs. HR that measured with ASCC system and AOCCs. Regression line (dotted) and 1:1 diagram (solid).

iglas. Not only Rs, but also Rp was reduced about $9.1 \%$, which agreed with those found by Musgrave and Moss (1961) and by Held (1990), i.e. 10-20\%. Moreover, Rp reduction was reported $10 \%$ by Leadley and Drake (1993), $12 \%$ by Pickering (1993), and $20 \%$ by Steduto (2002).

Overall, we could conclude that the reduction effect of the developed ASCC system was the least, and compatible for field measurement.

Leaking test of ASCC system The major concern on measuring $\mathrm{CO}_{2}$ flux using open-flow method is the sealing of the chamber. However the device is sophisticated, the risk of leaking is ever-present wherever there is a gradient of gas concentration between inside and outside the chamber. Because relative errors introduced by the measurement of fictitious fluxes corresponding gas leakages depend on the actual values of flux (Steduto, 2002), the verification of leakage in the ASCC is very important. Unlike other small canopy chambers which could be testified in laboratory by filling $\mathrm{CO}_{2}$ gas, the ASCC system was established in the field with enough scale for the measurement of flux under intra-individual interaction in crop, so that we substituted the verification test under non crop condition for ordinary leaking test. The whole NEP under non-crop condition should be originated from HR. The NEP and HR should have the similar exchange pattern. Therefore, the verification of leaking test was followed by the analysis of ASCC

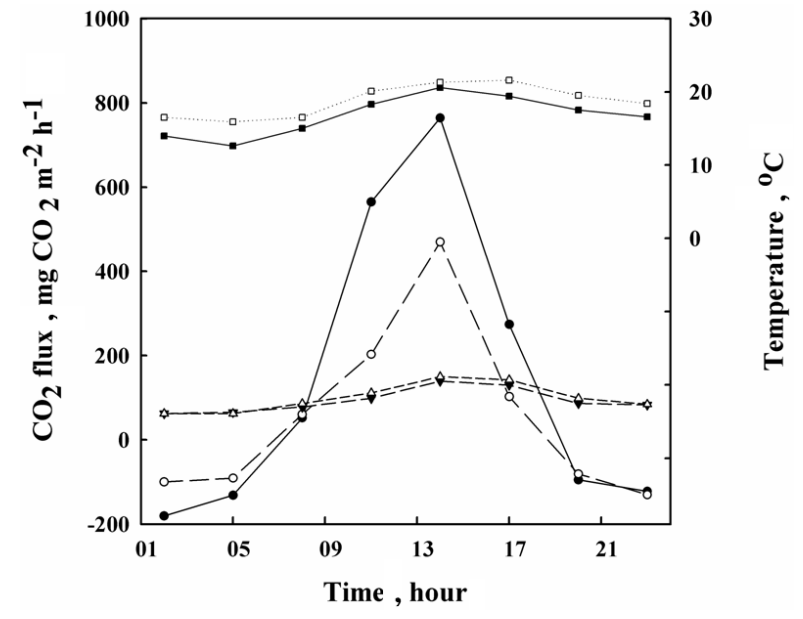

Fig. 5. Diumal variation of NEP, HR and air temperature at clear and cloudy day: filled circle indicate clear day NEP; open circle indicate cloudy day NEP; filled triangle indicate clear day HR; open triangle indicate cloudy day HR; filled square indicate clear day temperature; open square indicate cloudy day temperature.

and AOCC data every 2 minutes from 18 to 23 April 2005.

According to the literature reported, Held (1990) estimated 4\% of leakage and Garrity (1984) reported that observed leakages during the sampling time were negligible without providing quantitative information. In our field comparison, daily NEP on average was 42.8 \pm 18.7 and $42.5 \pm 18.6 \mathrm{mg} \mathrm{CO}_{2} \mathrm{~m}^{2} \mathrm{~h}^{-1}$ for daily $\mathrm{HR}$, namely $4.4 \%$ of mean leakage error. There was a strong relationship between NEP and HR (Fig. $4: \mathrm{r}^{2}=0.956^{* * *}$ ), and both set of results showed similar daily pattern of soil respiration depending on temperature. Significant correlation $\left(\mathrm{r}^{2}=0.978^{* *}\right)$ between NEP and HR verified that the measured NEP with ASCC system resulted from HR inside the ASCC.

Field measurement with ASCC system The aim of developing for ASCC system is to determine accurately seasonal, daily and real-time carbon flux in field under natural environmental conditions. To monitor the temporal NEP changes under natural field condition, we compared two climatic conditions (a clear and cloudy day) (Fig. 5). Daily average NEPs of a clear and cloudy day (with $30.5 \mathrm{~mm}$ precipitation) were $140 \mathrm{mg} \mathrm{CO}_{2} \mathrm{~m}^{-2}$ $\mathrm{h}^{-1}$ and $38.6 \mathrm{mg} \mathrm{CO}_{2} \mathrm{~m}^{-2} \mathrm{~h}^{-1}$, respectively. Because of strong correlation between NEP and solar radiation (a clear day; $r^{2}=0.953$, a cloudy day; $r^{2}=0.928$ : Fig. 6a), change of light environmental condition by rainfall caused the inhibition of barley photosynthesis mech- 

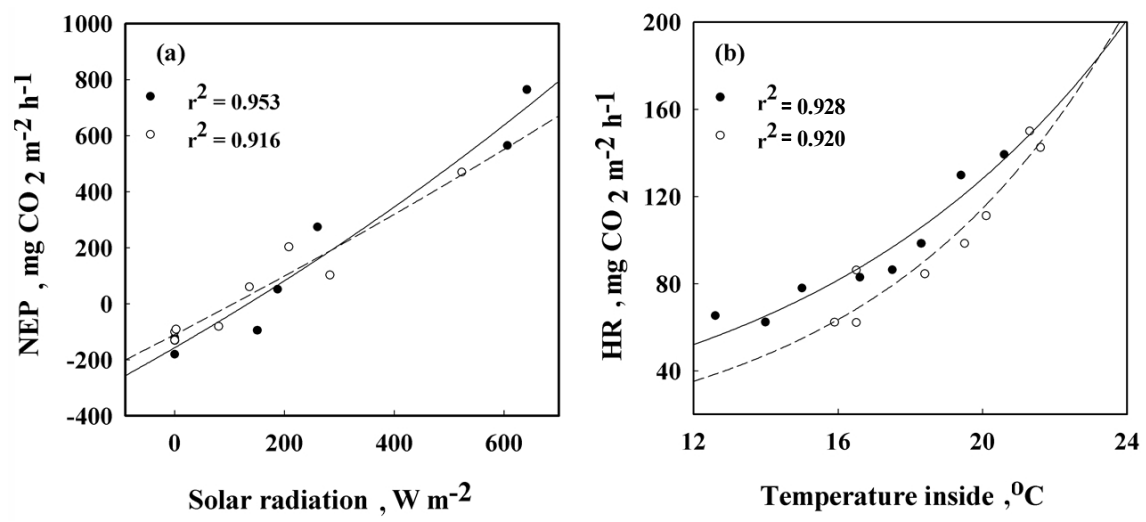

Fig. 6. Comelationship between NEP and solar radiation (a), and HR and soil temperature (b) at clear and cloudy day: filled circle for clear day; open circle for cloudy day.

anism, and eventually, amount of $\mathrm{CO}_{2}$ uptakes on a cloudy day showed relatively smaller compared with a clear day. However, HR measured with AOCC system showed strong correlation with soil temperature (a clear day; $r^{2}=0.928$, a cloudy day; $r^{2}=0.920$ : Fig. $6 b$ ). Similarly, a sudden decrease of photosynthesis was detected just after watering plant in indoor chamber experiment (van Iersel and Bugbee, 2000). It seemed to be the similar effect of rainfall in outdoor field condition. On a clear night, NEP showed -180.6 -95.0 $\mathrm{mg} \mathrm{CO}_{2} \mathrm{~m}^{-2} \mathrm{~h}^{-1}$ $\left(\mathrm{CO}_{2}\right.$ release to atmosphere) due to the plant respiration, then it showed 52.0 764.1 $\mathrm{mg} \mathrm{CO}_{2} \mathrm{~m}^{-2} \mathrm{~h}^{-1}$ on a clear day because of photosynthesis. Greer (1995) showed that plant photosynthesis was high with the light, and it was a good agreement with our result. Similar patterns were found on a cloudy day (-120.0 - $90.9 \mathrm{mg}$ $\mathrm{CO}_{2} \mathrm{~m}^{-2} \mathrm{~h}^{-1}$ of NEP without sunlight and 60.6 369.8 $\mathrm{mg} \mathrm{CO} 2 \mathrm{~m}^{-2} \mathrm{~h}^{-1}$ with sunlight), and NEP decreasing time was coinciding with the rainfall. In case of short term result of HR using the AOCC, it showed similar value on both a clear and cloudy day $\left(62.4 \sim 139.3 \mathrm{mg} \mathrm{CO}_{2}\right.$ $\mathrm{m}^{-2} \mathrm{~h}^{-1}$ for a clear day and $62.2 \sim 150.0 \mathrm{mg} \mathrm{CO}_{2} \mathrm{~m}^{-2} \mathrm{~h}^{-1}$ for a cloudy day), and we found the strong correlation with soil temperature $\left(r^{2}=0.9117^{* *}\right.$ for a clear day, and $\mathrm{r}^{2}=0.8973^{* *}$ for a cloudy day).

The ASCC system In $\mathrm{CO}_{2}$ flux study on crop-field, micrometeorological approach and small-scale canopy chamber method for individual plant have been used in general. Because of the requirement of large spatialscale, the micrometeorological approach is limited in application for typical small-scale agronomic plot experiments. Besides, the small-scale canopy chamber used to be installed in growth chamber, is appropriate for study on plant response according to the environment controlled condition.

However it is raised, several questions such as that individual plant may not be representative of the entire crop and growth chamber may not be reflective of natural environment. At the same time, leakage during measurement time and the environmental changes due to the greenhouse effect are another problems facing usage of automated chamber system. For this, small scale automated chamber system using the driving force of air-cylinder or DC motor for sealing the lid to chamber is needed.

In case of ASCC system, each plot keeps natural environment open to minimize the chamber effect. When it comes to measuring time, the ASCC slides along the base frame and covers the target plot. To ensure the sealing condition during measurement time, air pumped flexible silicon tube fills up the gap between ASCC and base frame. Effects of Differential air and soil temperature on opened and closed ASCC condition were less than $2^{\circ} \mathrm{C}(99.1 \pm 1.5,99.2 \pm 1.2 \%)$, respectively. As for light environment, existing chamber systems were reduced about $10-20 \%$ in Rs (Leadley and Drake 1993; Steduto 2002; Weinstock, 1982), whereas the ASCC system was so effective that it showed about $7.4 \%$ of reduction. Also the reduction of $9.2 \%$ in Rp denoted the fewer disturbances in light condition by ASCC system. As a result of leaking test, it showed $4.2 \%$ of leakage, which was in agreement with the result of Garrity (1984) showing 4\% of leakage.

Comparing the NEP of a cloudy day to a clear day, we could possibly monitor the point that the NEP decreased during rainfall. Additionally, measuring technique which covered 24 hours data including night 
time, we could reduce the possibility of overestimate NEP using pick point measuring method during day time (about $16 \%$ overestimate using 10 a.m. and 4 p.m. data).

From the results of our study, we suggest that the open-flow dynamic ASCC system is a useful tool for continuous short-term and long-term monitoring of $\mathrm{CO}_{2}$ flux with minimized disturbance on natural environment condition in crop-field. Based on ASCC system data would help us to better understand the relationships between real-time $\mathrm{CO}_{2}$ flux and environmental factors in crop-field, and the possibility of crop-field as a potential carbon source or sink.

Furthermore, the convertibility by transforming frames makes it possible to remount the ASCC system not only in crop field but also in other ecosystems, which has relatively lower canopy such as grassland and shrubs. As a result, the ASCC system can be applied to research on any gas exchange in any ecosystem for further study.

\section{Acknowledgements}

This study was carried out with the support of "Development of emission factors and Assessment of emission for $\mathrm{N}_{2} \mathrm{O}$ at Cropland in Korea (Project No: PJ006 783032012)", Rural Development Administration, Republic of Korea.

\section{References}

Baldocchi, D.D., B.B. Hincks, and T.P. Meyers. 1988. Measuring biosphere-atmosphere exchanges of biologically related gases with micrometeorological methods. Ecology 69:1331-1340.

Edwards, N.T. and J.S. Riggs. 2003. Automated monitoring of soil respiration: A moving chamber design. Soil Sci. Soc. Am. J. 67:1266-1271

Garrity, D.P., C.Y. Sullivan, and D.G. Watts. 1984. Rapidly determining sorghum canopy photosynthetic rates with a mobile field chamber. Agron. J. 76:163-165.

Greer, D.H. 1995. Effect of daily photon receipt on the susceptibility of dwarf bean (Phaseolus vulgaris L.) leaves to photoinhibition of photosynthesis. Planta 197:31.

Held, A.A., P. Steduto, F. Orgaz, A. Matista, and T.C. Hsiao. 1990. Bowen ratio/energy balance technique for estimating crop net $\mathrm{CO}_{2}$ assimilation, and comparison with a canopy chamber. Theor. Appl. Climatol. 42:203-213.

Katsura, K., S. Maeda, T. Horie, and T. Shiraiwa. 2006. A multichannel automated chamber system for continuous measurement of carbon exchange rate of rice canopy. Plant Prod. Sci. 9:152-155.

Leadley, P.W. and B.G. Drake. 1993. Open top chambers for exposing plant canopies to elevated $\mathrm{CO}_{2}$ concentration and for measuring net gas exchange. Plant Ecol. 104-105(1):3-15.

Livingstone, G.P. and G.L. Hutchinson. 1995. Enclosure-based measurement of trace gas-exchange: application and for sources off error. p. 14-51. In P.A. Matson et al. (ed.) Biogenic Trace Gases: Measuring Emissions from soil and Water. Blackwell Scientific Publication, London. UK.

Musgrave, R.B. and D.N. Moss. 1961. Photosynthesis under field conditions. I. A portable, closed system for determining net assimilation and respiration of corn. Crop Sci. 1:37-41.

Pickering, N.B., J.W. Jones, and K.J. Boote. 1993. Evaluation of the portable chamber technique for measuring canopy gas exchange by crops. Agr. Forest Meteorol. 63:239-254.

Raich, J.W. and W.H. Schlesinger. 1992. The global carbon dioxide flux in soil respiration and its relationship to vegetation and climate. Tellus 44B:81-99.

Reicosky, D.C. 1985. Advances in evapotranspiration measured using portable field chamber. p. 79-86. In Proceedings of the National Conference on Advances in Evapotranspiration. American Society of Agricultural Engineering, Chicago, IL, USA.

Reicosky, D.C., B.S. Sharratt, J.E. Ljungkull, and D.G. Baker. 1983. Comparison of alfalfa evapotranspiration measured by a weighing lysimeter and a portable chamber. Agric. Meteorol. 28:205-211

Reicosky, D.C., S.W. Wagner, and O.J. Devine. 1990. Methods of calculating carbon dioxide exchange rates for maize and soybean using a portable field chamber. Agr. Forest Meteorol. 28:205-211.

Steduto, P., Ö. Cetinkökü, R. Albrizio, and R. Kanber. 2002. Automated closed-system canopy-chamber for continuous field-crop monitoring of $\mathrm{CO}_{2}$ and $\mathrm{H}_{2} \mathrm{O}$ fluxes. Agr. Forest Meteorol. 111:171-186.

Suh, S.U., Y.M. Chun, N.Y. Chae, J. Kim, J.H. Lim, M. Yokozawa, M.S. Lee, and J.S. Lee. 2006. A chamber system with automatic opening and closing for continuously measuring soil respiration based on an open-flow dynamic method. Ecol. Res. 21:405-414.

van Iersel, M.W. and B. Bugbee. 2000. A multiple chamber, semicontinuous, crop carbon dioxide exchange system: design, calibration, and data interpretation. J. Amer. Soc. Hort. Sci. 125:86-92.

Wagner, S.W. and D.C. Reicosky. 1992. Closed chamber effects on leaf temperature, canopy photosynthesis, and evapotranspiration. Agron. J. 84:731-738.

Weinstock, L., W.J. Kender, and R.C. Musselman. 1982. Microclimate within open-top air pollution chambers and its relation to grapevine physiology. J. Amer. Soc. Hort. Sci. 107:923-929. 